\title{
Upregulation of miR-572 transcriptionally suppresses SOCS1 and p21 and contributes to human ovarian cancer progression
}

\author{
Xin Zhang ${ }^{1,2, *}$, Junling Liu ${ }^{3, *}$, Dan Zang ${ }^{1}$, Shu Wu ${ }^{2}$, Aibin Liư ${ }^{4}$, Jinrong Zhu ${ }^{4}$, Geyan \\ $\mathbf{W u}^{4}$, Jun $\mathrm{Li}^{4}$ and Lili Jiang ${ }^{1}$ \\ 1 Department of Pathophysiology, Guangzhou Medical University, Guangzhou, China \\ ${ }^{2}$ Department of Experimental Research, State Key Laboratory of Oncology in Southern China, Sun Yat-sen University Cancer \\ Centre, Guangzhou, China \\ ${ }^{3}$ Department of Medical Oncology, State Key Laboratory of Oncology in Southern China, Sun Yat-sen University Cancer \\ Center, Guangzhou, China \\ ${ }^{4}$ Department of Biochemistry, Zhongshan School of Medicine, Sun Yat-sen University, Guangzhou, Guangdong, China \\ * These authors have contributed equally to this work \\ Correspondence to: Lili Jiang, email: jianglili126@163.com
}

Keywords: ovarian cancer, miR-572, proliferation, SOCS1, p21

Received: January 27, $2015 \quad$ Accepted: March 05, 2015

Published: March 30, 2015

This is an open-access article distributed under the terms of the Creative Commons Attribution License, which permits unrestricted use, distribution, and reproduction in any medium, provided the original author and source are credited.

\section{ABSTRACT}

Ovarian cancer is a gynecological malignancy with high mortality rates worldwide and novel diagnostic and prognostic markers and therapeutic targets are urgently required. The suppressor of cytokine signaling 1 (SOCS1) and cyclin-dependent kinase inhibitor 1A ( p21 $^{\mathrm{KIP}}$ ) are known to regulate tumor cell proliferation. However, the mechanisms that regulate these genes have not yet been completely elucidated. In the present study, analysis of a published microarray-based high-throughput assessment (NCBI/E-MTAB-1067) and real-time PCR demonstrated that miR-572 was upregulated in human ovarian cancer tissues and cell lines. Kaplan-Meir analysis indicated that high level expression of $\mathbf{m i R}-572$ was associated with poorer overall survival. Ectopic miR-572 promoted ovarian cancer cell proliferation and cell cycle progression in vitro and tumorigenicity in vivo. SOCS1 and p21 were identified as direct targets of miR-572 and suppression of SOCS1 or p21 reversed the inhibitingfunction of miR-572-silenced cell on proliferation and tumorigenicity in ovarian cancer cells. Additionally, the expression of $\mathrm{miR}-572$ correlated inversely with the protein expression levels of SOCS1, p21 and positively with Cyclin D1 in ovarian carcinoma specimens. This study demonstrates that miR-572 post-transcriptionally regulates SOCS1 and p21 and may play an important role in ovarian cancer progression; miR572 may represent a potential therapeutic target for ovarian cancer therapy.

\section{INTRODUCTION}

Ovarian cancer is a gynecological malignancy with high mortality rates worldwide, and is the seventh most common cancer and the eighth most common cause of death due to cancer in females [1]. In 2012, 239,000 cases were diagnosed and 152,000 deaths due to ovarian cancer occurred worldwide [2]. The disproportionately high mortality rates and relatively poor prognosis of ovarian cancer can be attributed to the absence of clinical symptoms in early stage disease and the high failure rate for chemotherapy in advanced stage disease [3]. The fiveyear overall survival rate for early stage ovarian cancer is $70 \%-90 \%$ compared to only $20 \%$ for advanced stage disease [3]. In order to improve the survival of patients with ovarian cancer, it is important to identify novel prognostic markers and therapeutic targets [4-7].

Cancer is essentially a disease in which cells lose the normal checks on cell proliferation [8], and develops as a result of excessive cell proliferation. Therefore, exploration of the regulatory mechanisms that control tumor cell growth in order to target the cell proliferation machinery is an important strategy for 
cancer treatment $[8,9]$. As a prototypic member of the suppressor of cytokine signaling (SOCS) family, SOCS1 was initially defined as an attenuator of the signaling of numerous cytokines via a feedback loop mechanism [10-12]. Altered SOCS1 expression has been reported in a wide range of human cancers and it may represent a diagnostic or prognostic biomarker. For example, SOCS1 is frequently silenced by $\mathrm{CpG}$ island methylation in human hepatocellular carcinoma [13] and frequently inactivated by hypermethylation in multiple myeloma [14]. In human breast cancer, the mRNA expression of SOCS1 decreases as TNM stage increases, and high SOCS1 expression is significantly associated with earlier tumor stage and a better clinical outcome [15]. p21 plays essential roles in the cellular response to DNA damage, and functions as a regulator of cell cycle progression that its overexpression results in cell cycle arrest [16]. In a similar manner to SOCS1, p21 is expressed at higher levels in advanced stage head and neck cancer with longer overall survival [17]. Expression of p 21 has also been reported to correlate inversely with $\mathrm{T}$ classification and clinical stage in squamous cell carcinoma of the tongue [18]. Although the expression of SOCS1 is lost in many human tumors and p21 is reported to be downregulated in multiple malignancies [19-22], the mechanisms leading to these effects are complicated and poorly understood.

MicroRNAs (miRNAs), small non-coding RNAs containing 20 - 22 nucleotides, are involved in various biological processes such as cellular differentiation, proliferation, oncogenesis and angiogenesis [23-26]. It has been demonstrated that miRNAs play important roles during malignant progression by negatively regulating their target mRNAs via recognizing and binding their $3^{\circ}$ untranslated regions (3`UTRs) $[27,28]$. The identification of the post-translational regulatory function of miRNAs has provided novel insight into tumor suppressor gene expression. As the expression of numerous miRNAs has been found to closely correlate with multiple biological aspects of cancer progression, miRNAs are considered to represent potential therapeutic targets for cancer [27-29].

Herein, we report that miR-572 is significantly upregulated in ovarian cancer and that the expression of miR-572 correlates with progression and overall survival in human ovarian cancer. Ectopic miR-572 promoted while inhibition of miR-572 reduced - the proliferation, cell-cycle progression and tumorigenicity of ovarian cancer cells in vitro. Furthermore, we demonstrate that miR-572 directly targets and downregulates SOCS1 and p21 via recognizing their $3^{\prime}$ UTRs, and downregulation of SOCS1 or p21 was essential for the miR-572-mediated effects in ovarian cancer cells. This study demonstrates that miR-572 plays an important role in the development and progression of ovarian cancer and may represent as a potential therapeutic target for ovarian cancer.

\section{RESULTS}

\section{miR-572 is upregulated and correlates with overall survival in human ovarian cancer}

By analyzing a published microarray-based highthroughput assessment (NCBI/E-MTAB-1067), we found that miR-572 was upregulated significantly $(P<0.0001)$ in human ovarian cancer tissues compared to normal ovarian tissues (Figure 1A). Expression of miR-572 was further examined in 108 archived clinical ovarian cancer specimens. As shown in Figure 1B, miR-572 was expressed at low levels in stage I and II tumors, markedly increased in stage III tumors and was further elevated in stage IV ovarian cancer. The Chi-squared test revealed that the levels of miR-572 strongly correlated with FIGO stage $(P<0.05$; Figure 1B, Supplemental Table 2). Kaplan-Meier analysis and the log-rank test indicated that a high level of miR-572 expression was associated with significantly shorter overall survival $(P<0.001$; Figure $1 \mathrm{C}$, Supplemental Table 2). This data suggests a possible link between high-level miR-572 expression and the progression of human ovarian cancer, and highlights miR572 may have potential value as a prognostic biomarker in ovarian cancer.

Real-time PCR analysis revealed that miR-572 was significantly overexpressed in 12 freshly-collected ovarian cancer samples compared to two normal ovarian tissues (Figure 1D). In agreement with these observations, upregulation of miR-572 was confirmed in 13 ovarian cancer cell lines compared with a control normal ovarian epithelial cell line (HOSEpiC; Figure 1E). Collectively, these results strongly indicate that miR-572 is upregulated in ovarian cancer.

\section{Overexpression of miR-572 promotes proliferation and cell cycle progression in ovarian cancer cells}

To investigate the biological function of miR-572 in the development and progression of ovarian cancer, SKOV3 and OVCAR3 ovarian cancer cells stably expressing miR-572 were established (Supplemental Figure 1). The MTT assay demonstrated that ectopic overexpression of miR-572 significantly increased the growth rate of both SKOV3 and OVCAR3 cells (Figure $2 \mathrm{~A})$. The colony formation assay revealed that ectopic overexpression of miR-572 markedly enhanced the growth ability of both SKOV3 and OVCAR3 cells, as indicated by increased colony numbers and sizes (Figure 2B). The level of DNA synthesis, as examined using the BrdUrd incorporation assay, was significantly elevated in miR-572 transduced cells compared to vector control cells (Figure 2C). Furthermore, cell cycle analysis showed ectopic overexpression of miR-572 significantly 
increased the percentage of cells in the $\mathrm{S}$ phase and decreased the percentage of cells in the G1/G0 peak (Figure 2D). Collectively, these results demonstrate that miR-572 functions to enhance proliferation and cell cycle progression in ovarian cancer cells.

\section{Inhibition of miR-572 attenuates proliferation and cell cycle progression in ovarian cancer cells}

Next, loss-of-function studies using a miR-572 inhibitor (miRZip-572) were performed to confirm the biological function of miR-572 in ovarian cancer progression. As shown in Figure 3A and 3B, suppression of miR-572 via transfection of the miR-572 inhibitor significantly decreased the growth rate of both ovarian cancer cell lines compared the respective negative control (miRZip-Vector) cells. The level of DNA synthesis was also significantly suppressed in miR-572-inhibited cells compared to control cells (Figure 3C). In addition, flow cytometry revealed a significant increase in the percentage of cells in the $\mathrm{G} 1 / \mathrm{G} 0$ phase and decrease in the percentage of cells in the S phase in miR-572 inhibited cells (Figure $3 \mathrm{D})$. These results suggest that downregulation of miR572 inhibits proliferation, reduces tumorigenicity and prevents cell cycle progression in ovarian cancer cells.
A

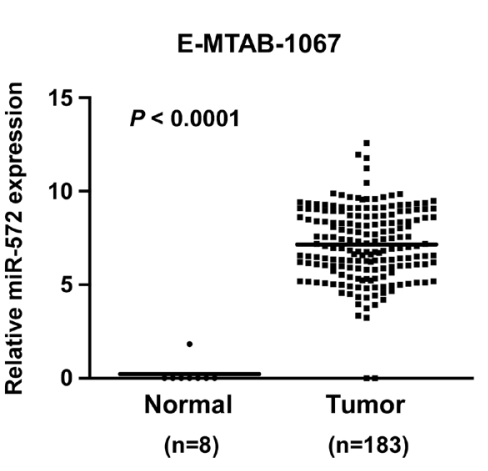

D
B

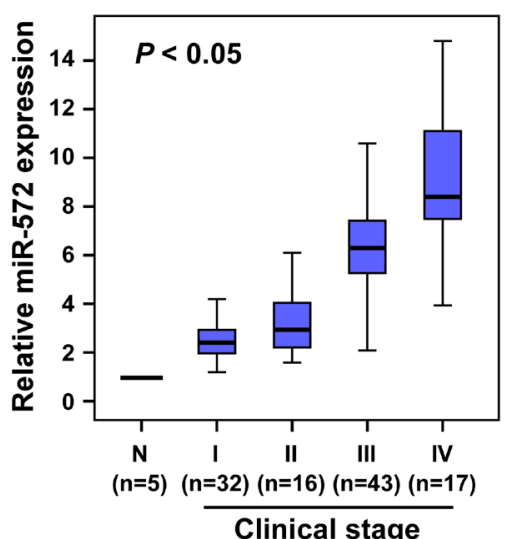

C

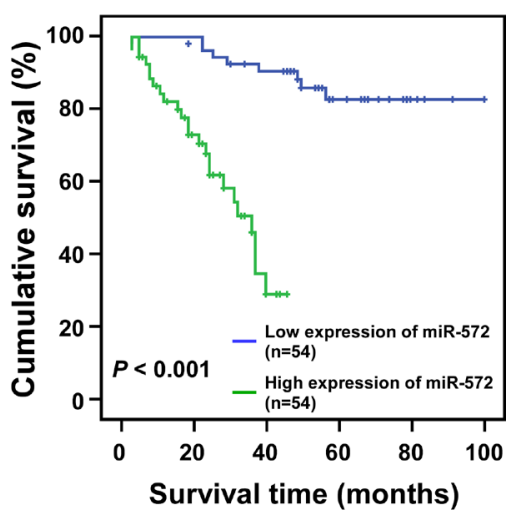

E
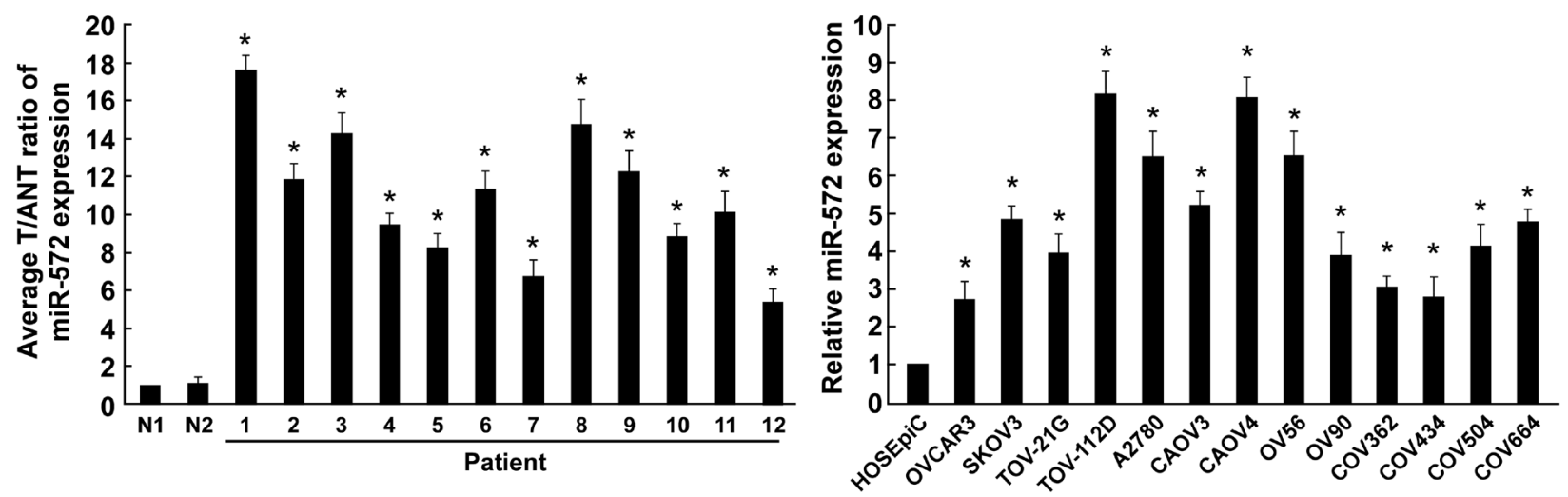

Figure 1: miR-572 is upregulated in ovarian cancer. (A) Analysis of a public microarray data revealed that miRNA-572 was upregulated in human ovarian cancer tissues $(n=183)$ compared with normal ovarian tissues $(n=8 ; P<0.0001$; NCBI/E-MTAB-1067). (B) Real-time PCR analysis of miR-572 expression in different clinical stages of human ovarian cancer. Transcript levels were normalized to U6 expression. The boundaries of the boxes represent the lower and upper quartiles; the lines within the boxes and whiskers denote the median and outer limits, respectively. (C) Kaplan-Meier analysis of overall survival for patients with ovarian cancer stratified by low miR572 ( $\leq$ median, $n=54$ ) and high miR-572 ( $>$ median, $n=54$ ) expression. (D) Real-time PCR analysis of miR-572 expression in 12 freshlyisolated ovarian cancer tissue specimens and two normal ovarian tissue specimens. (E) Real-time PCR analysis of miR-572 expression in 13 ovarian cancer cell lines and a normal ovarian epithelial cell line (HOSEpiC). Transcript levels were normalized to U6 expression. Experiments were repeated at least three times with similar results; values are mean $\pm \mathrm{SD} ; * P<0.05$. 


\section{MicroRNA-572 suppresses the tumorigenicity of ovarian cancer cells both in vitro and in vivo}

The anchorage-independent growth assay was performed to examine the effects of miR-572 on the tumorigenicity of ovarian cancer cells. Ovarian cancer cells stably expressing miR-572 formed higher numbers and larger colonies than the control cells, while inhibition of miR-572 led to the formation of fewer and smaller colonies (Figure 4A and 4B).

The biological effect of miR-572 on ovarian cancer progression was further examined using an in vivo tumor model. The miR-572-transduced ovarian cancer cells and miR-572-silenced cells, or the corresponding control cells, were subcutaneously injected into the dorsal flank of nude mice (Supplemental Figure 2). As shown in Figure 4C$\mathrm{E}$, the tumors formed by miR-572- transduced ovarian cancer cells were larger, in both size and weight, than the corresponding control tumors, whereas the tumors formed by miR-572- silenced ovarian cancer cells were smaller in size and weight than the corresponding control tumors. These data indicate that miR-572 plays a pivotal role in ovarian cancer progression in vivo.
A

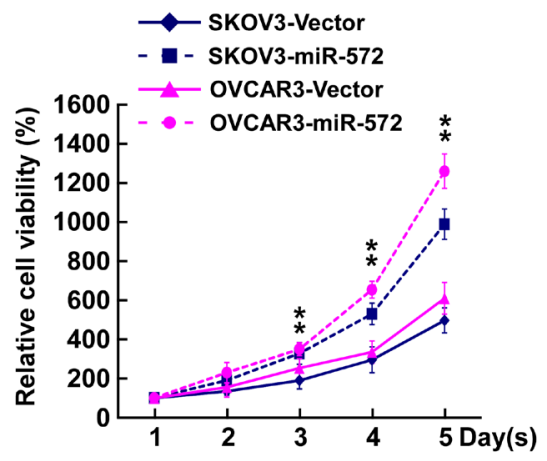

B

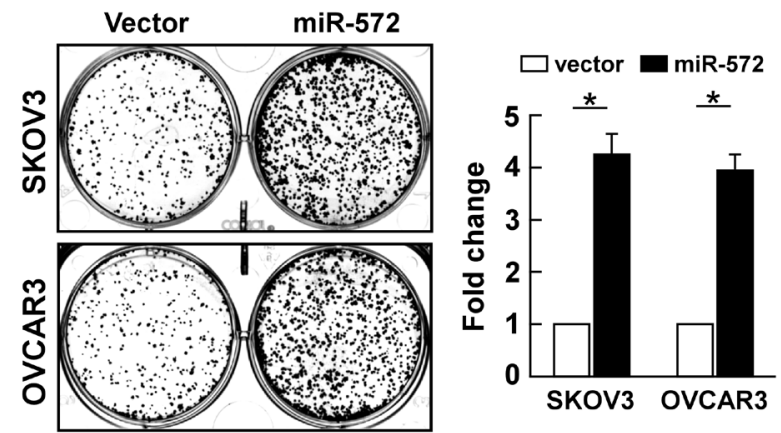

C
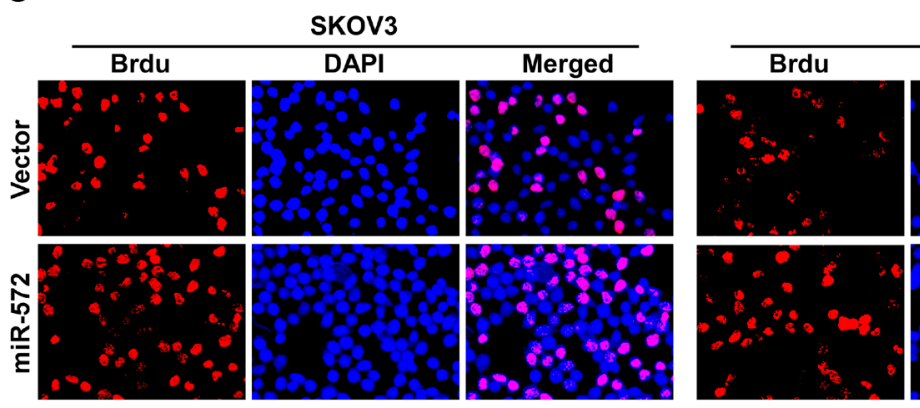

OVCAR3
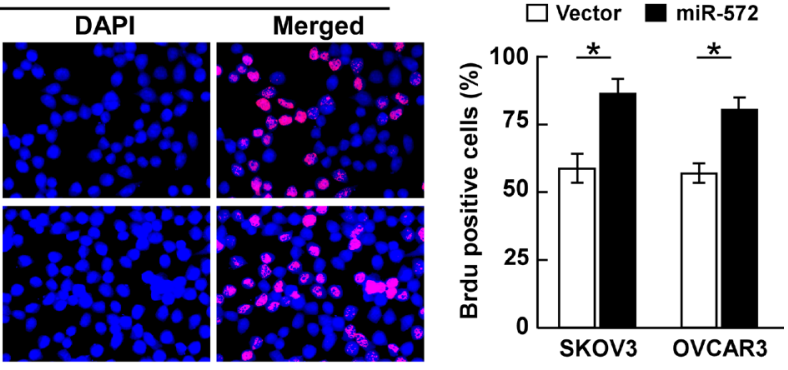

D

SKOV3
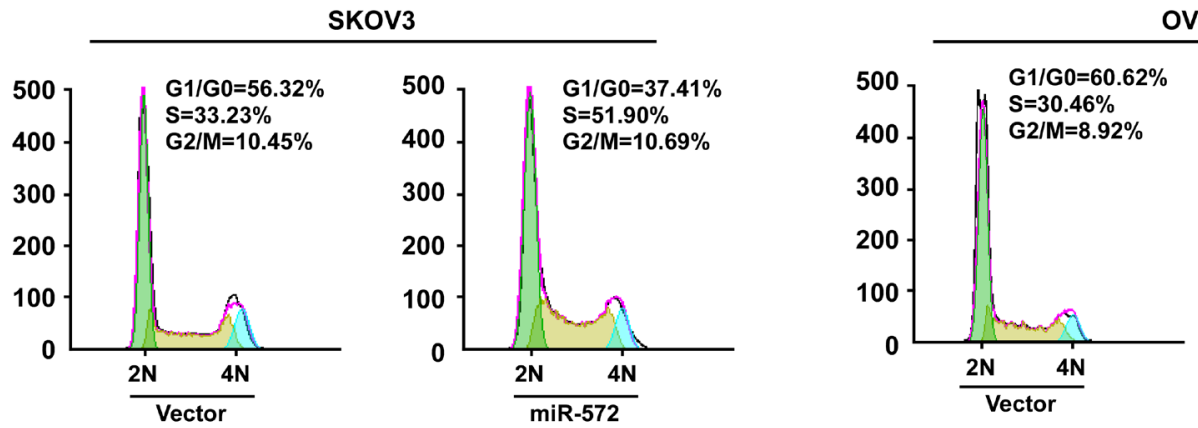

OVCAR3

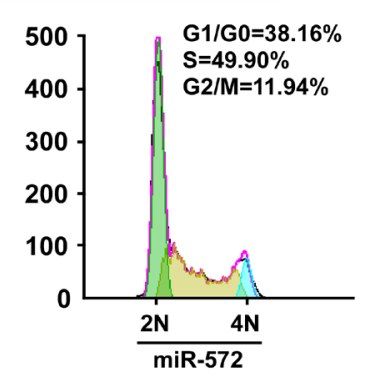

Figure 2: miR-572 promotes cell proliferation and cell-cycle progression in ovarian cancer cells. (A) Effects of ectopic overexpression of miR-572 on the proliferation of the indicated ovarian cancer cell lines, as analyzed by the MTT assay. (B) Representative micrographs (left) and quantification (right) of colonies formed by the indicated ovarian cancer cell lines at 10 days after inoculation in the colony formation assay. (C) Representative micrographs (left) and quantification (right) of BrdUrd incorporating-cells for the indicated ovarian cancer cells. (D) Flow cytometric analysis of the effect of miR-572 overexpression on cell cycle progression for the indicated ovarian cancer cells. Experiments were repeated at least three times with similar results; values are mean $\pm \mathrm{SD} ; * P<0.05$. 


\section{MicroRNA-572 directly suppresses SOCS1 and p21 in ovarian cancer cells}

In an attempt to identify the mRNA targets of miR572, we performed bioinformatic analysis using a publicly available algorithm (TargetScan 6.2). As shown in Figure $5 \mathrm{~A}$, SOCS1 and $p 21$, which are critical attenuators of cell proliferation and cell-cycle progression, were identified as potential targets of miR-572. Western blotting analysis showed that ectopic expression of miR-572 dramatically decreased, whereas inhibition of miR-572 increased, the protein expression levels of SOCS1 and p21 in both SKOV3 and OVCAR3 ovarian cancer cells (Figure 5B). Meanwhile, the expression of CyclinD1 was increased by ectopic expression miR-572, decreased by miR-572 inhibition (Figure 5B). Luciferase reporter plasmids containing regions of the 3 ' UTR of SOCS1 or $p 21$ were constructed and cotransfected into ovarian cancer cells with miR-572, miR-572 inhibitor or the corresponding negative controls. As shown in Figure 5C, miR-572
A

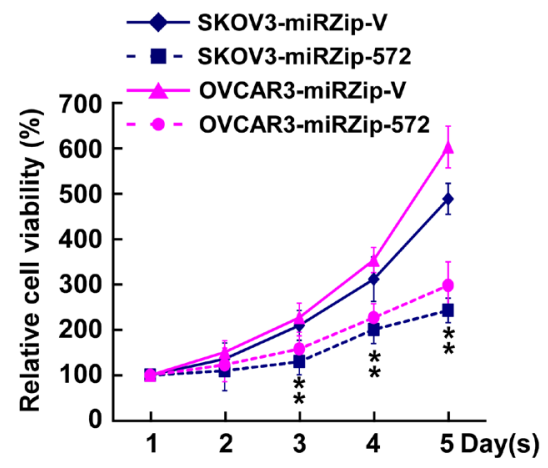

B



$\square$ miRZip-v $\square$ miRZip-572

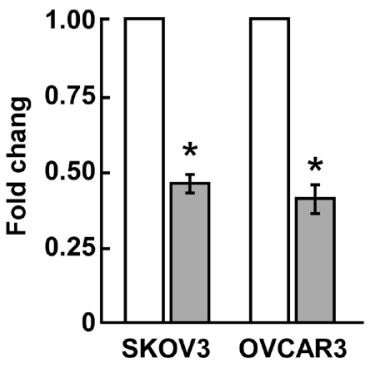

C
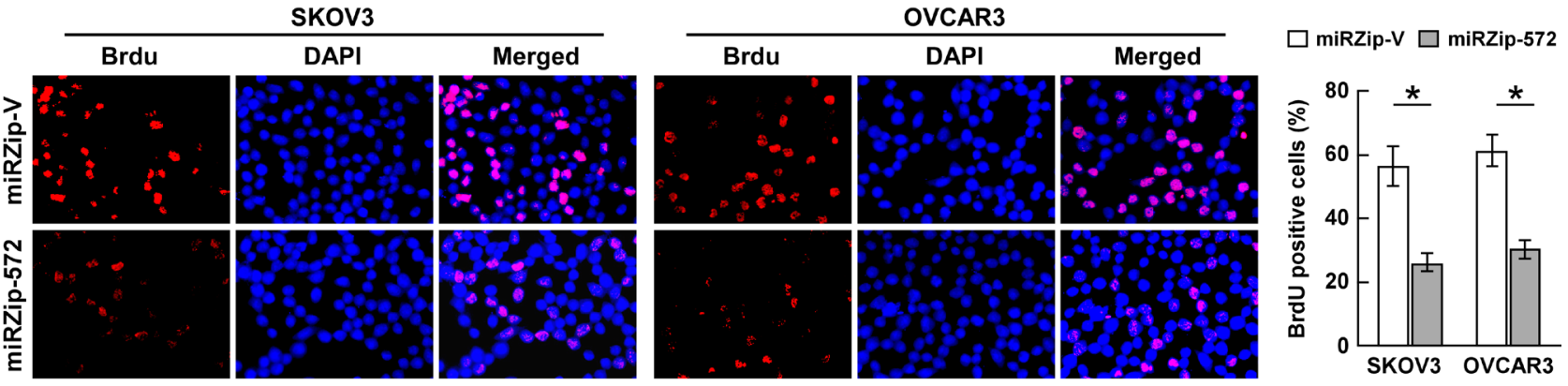

D

SKOV3



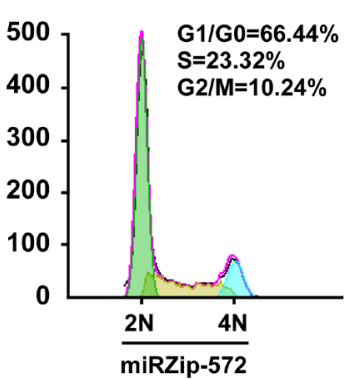

OVCAR3

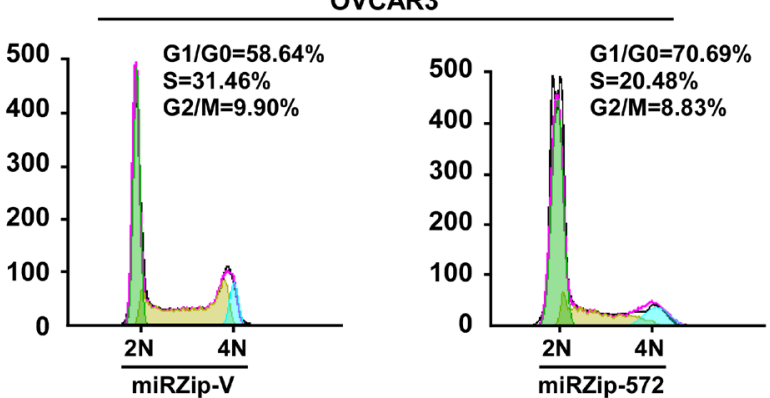

Figure 3: Inhibition of miR-572 reduces cell proliferation and cell-cycle progression in ovarian cancer cells. (A) Effects of ectopic miR-572 on the proliferation of the indicated ovarian cancer cell lines, as analyzed by the MTT assay. (B) Representative micrographs (left) and quantification (right) of colonies formed by indicated ovarian cancer cell lines at 10 days after inoculation in the colony formation assay. (C) Representative micrographs (left) and quantification (right) of BrdUrd incorporating-cells for the indicated ovarian cancer cells. (D) Flow cytometric analysis of the effects of miR-572 overexpression on cell cycle progression for the indicated ovarian cancer cells. Experiments were repeated at least three times with similar results; values are mean $\pm \mathrm{SD} ; * P<0.05$. 
significantly reduced the luciferase activity of the SOCS1 and $p 21$ reporter genes, whereas transfection of the miR-572 inhibitor upregulated the luciferase activity of the reporter genes. However, transfection of miR-572mut (miR-572 mutant) had no significant effect on the luciferase activity of the reporter genes (Figure 5C); and miR-572 also had no effect on the luciferase activity of the mutant reporter genes (Supplemental Figure 3). Taken together, these results confirm that SOCS1 and p21 are direct targets of miR-572.

\section{Suppression of SOCS1 or p21 are required for miR-572-induced cell proliferation and tumorigenesis in ovarian cancer}

To evaluate the effects of SOCS1 and p21 on miR572-induced ovarian cancer progression, we suppressed the expression of endogenous SOCS1 or p21 using specific siRNAs (Figure 5D). The colony formation assay indicated that silencing SOCS1 or $p 21$ increased the proliferation of ovarian cells transfected with the miR572 inhibitor (Figure 5E); similar results were observed in the anchorage-independent growth assay (Figure 5F).
As shown in Figure 5G, silencing SOCS1 or $p 21$ in miR572-inhibitor transfected cells also increased the mRNA and protein expression of Cyclin D1, a well-characterized regulator of cell proliferation. These results suggest that silencing SOCS1 or p21 in miR-572-repressed cells reversed the negative effect of the miR-572 inhibitor on ovarian cancer cell proliferation and tumorigenesis.

\section{Clinical relevance of miR-572, SOCS1, p21 and Cyclin D1 in ovarian cancer}

Finally, to examine whether miR-572-mediated suppression of SOCS1 and p21 in ovarian cancer is clinically relevant, seven freshly collected ovarian cancer samples and two normal ovarian tissues were obtained for further study. As shown in Figure 6A and 6B, the levels of miR-572 correlated with the protein expression levels of SOCS1 $(r=-0.742, P=0.022), \mathrm{p} 21(r=-0.762, P=$ $0.017)$ and Cyclin D1 $(r=0.739, P=0.023)$. These results suggest that miR-572 decreases the expression of SOCS1 and p21 and increases Cyclin D1 expression, consequently resulting in an aggressive phenotype and poorer prognosis in ovarian cancer (Figure 7).
A

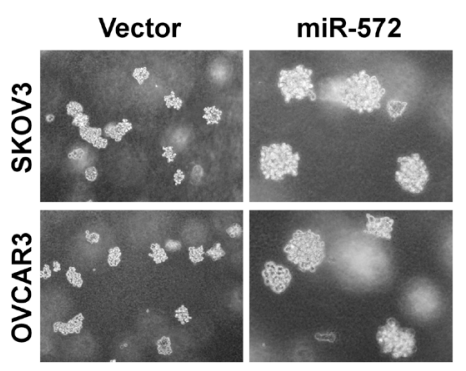

C

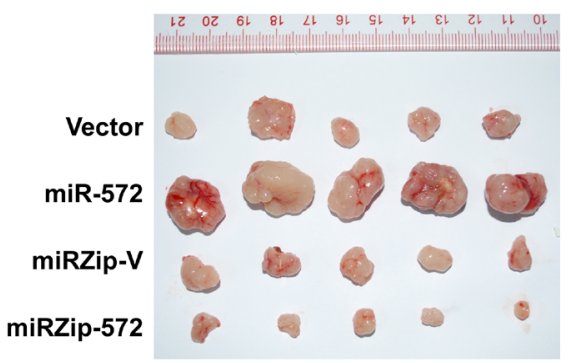

B

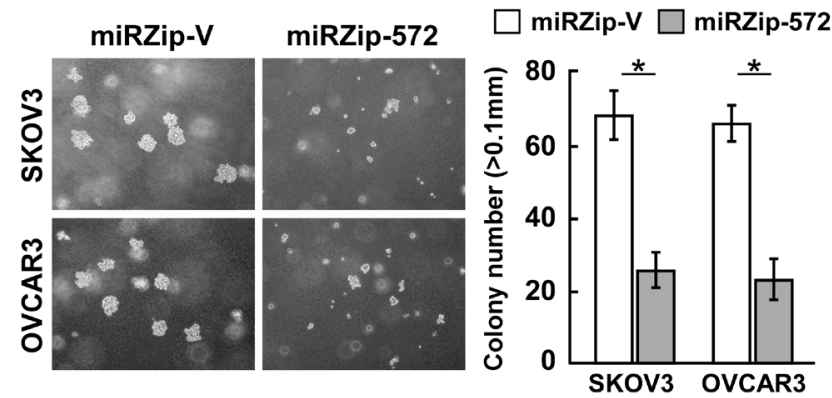

E


Figure 4: MiR-572 suppresses tumorigenicity of ovarian cancer cell both in vitro and in vivo. (A) and (B) Representative micrographs (left) and quantification (right) of colony formation in vitro in the anchorage-independent growth assay. Colonies $>0.1 \mathrm{~mm}$ were scored. (C) Representative images of tumors formed by the indicated cells in the tumor xenograft model. (D) Average tumor volumes $\left(\mathrm{mm}^{3}\right)$ for the indicated cells after inoculation. (E) Weight of the tumors formed by the indicated cells. * or $\# P<0.05$. 
A

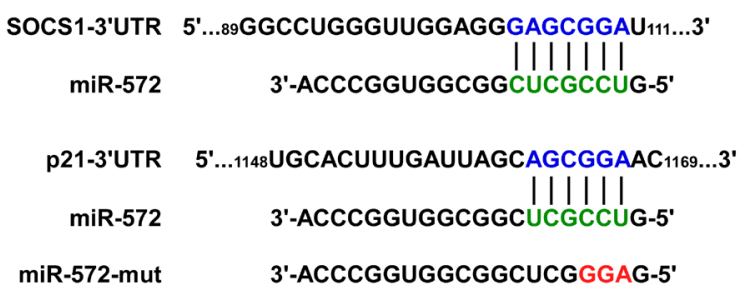

C

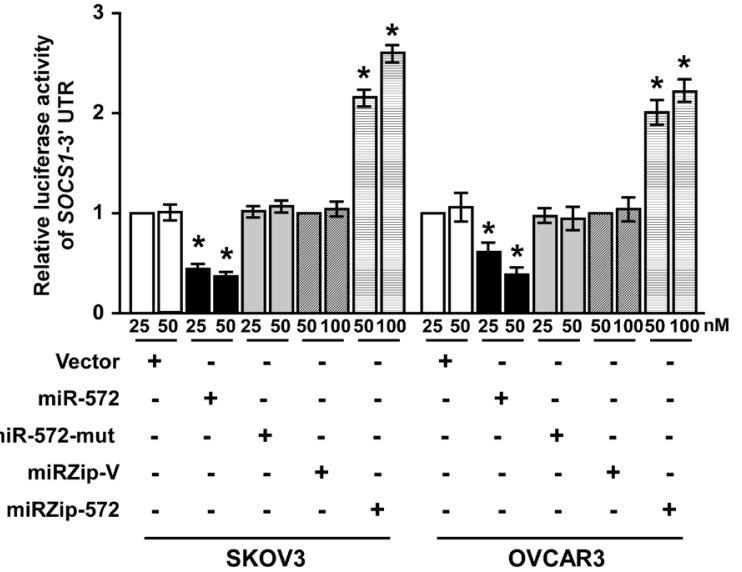

D

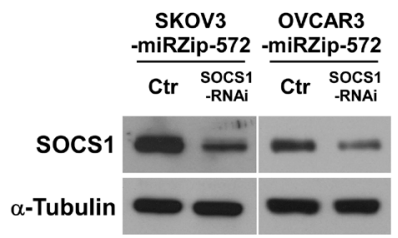

$\mathbf{F}$



G
B

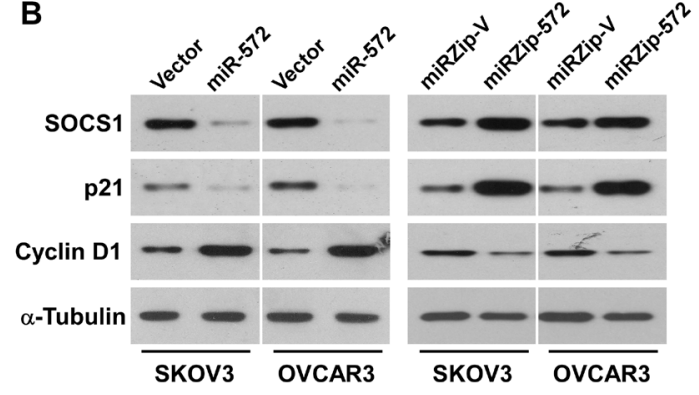

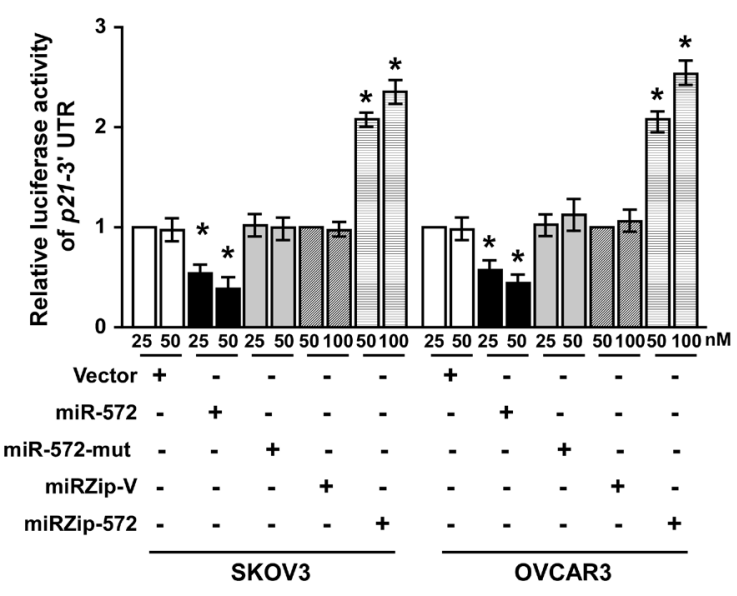

E
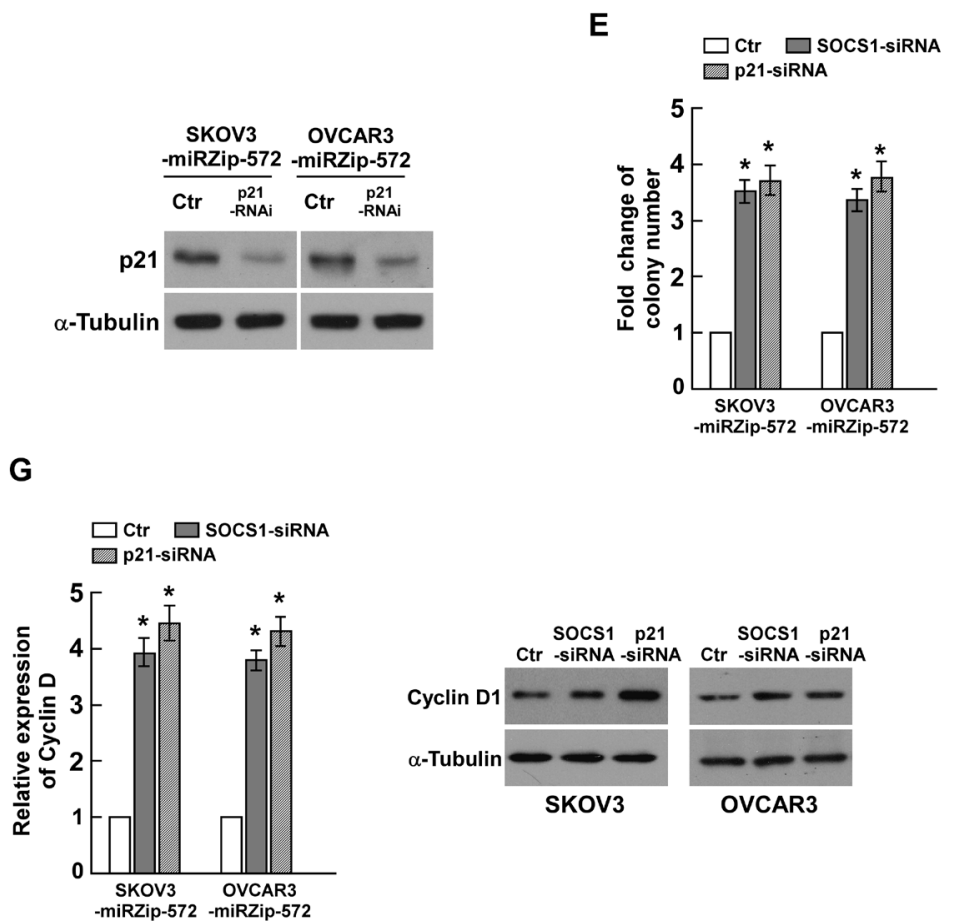

Figure 5: SOCS1 and p21 are essential for miR-572-mediated proliferation in ovarian cancer. (A) Putative target sites for miR-572 in the 3' UTRs of SOCS1 and $p 21$ and the sequence of miR-572 mutant (miR-572-mut). (B) Western blotting analysis of the protein levels of SOCS1, p21 and Cyclin D1 in the indicated cells. (C) Luciferase assays of the indicated cells co-transfected with the pGL3-SOCS1 or 21 reporter genes and miR-572, miR-572 inhibitor, miR-572 mutant (miR-572-mut) or the respective controls. (D) Western blotting analysis of the protein levels of SOCS1 and p21 in the indicated cells transfected with specific siRNAs, respectively. (E) Quantification of colonies formed by the indicated ovarian cancer cell lines in the colony formation assay. (F) Quantification of colonies formed by the indicated ovarian cancer cell lines in the anchorage-independent growth ability assay. (G) Real-time PCR analysis of Cyclin D1 mRNA expression and western blotting analysis of Cyclin D1 protein expression. Experiments were repeated at least three times with similar results; values are mean $\pm \mathrm{SD} ; * P<0.05$. 


\section{DISCUSSION}

The discovery of effective diagnostic and prognostic biomarkers and therapeutic methods is urgently required for the diagnosis and treatment of ovarian cancer. Numerous studies have shown that miRNAs may represent valuable diagnostic and prognostic markers for cancer [32-35]. miR-572 is overexpressed in the serum of patients with nasopharyngeal carcinoma and renal cell carcinoma, and was used to construct a miRNA signature for patients prognosis [36, 37], and $\mathrm{Li}$ et al. found $\mathrm{miR}$ 572 was significantly overexpressed in peripheral $\mathrm{T}$ cell lymphoma, not otherwise specified (PTCL-NOS) [38]. The expression of miR-572 in ovarian cancer has not previously been investigated. This study demonstrates that
miR-572 is significantly upregulated in ovarian cancer. Additionally, the expression of miR-572 correlated with ovarian cancer progression and overall patient survival, indicating that upregulation of miR-572 may contribute to the development of ovarian cancer and may have potential as a diagnostic and prognostic biomarker for ovarian cancer.

In the present study, SOCS1 and $p 21$ were both identified as direct targets of miR-572 and could be suppressed by overexpression of miR-572, which in turn increased the proliferation and cell cycle progression of ovarian cancer cells in vitro and promoted tumorigenesis in an in vivo model of ovarian cancer. These findings are in agreement with the known roles of SOCS1 and p21 in cancer. Induction of SOCS1 by activated signal transducers and activators of transcription (STATs) can
A

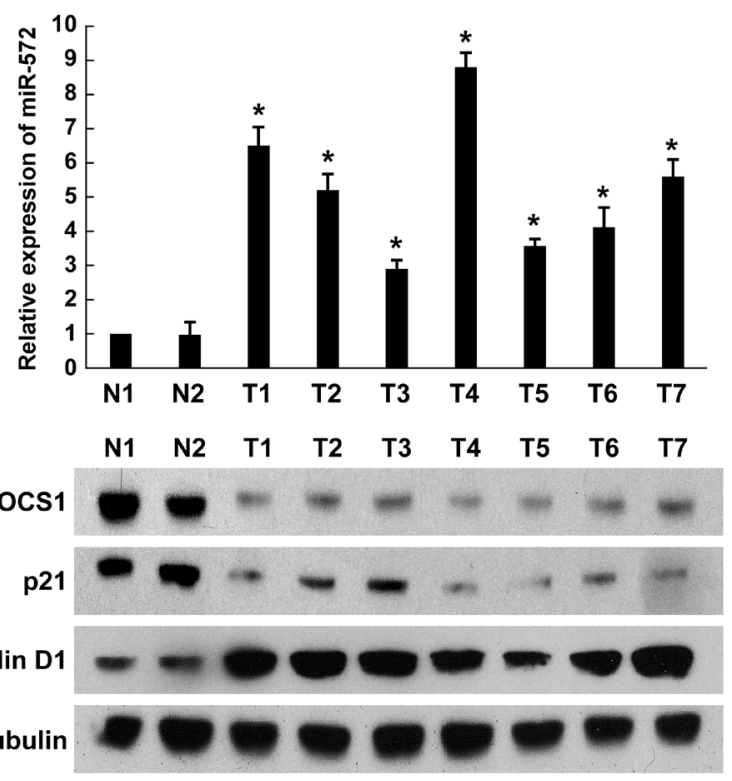

B
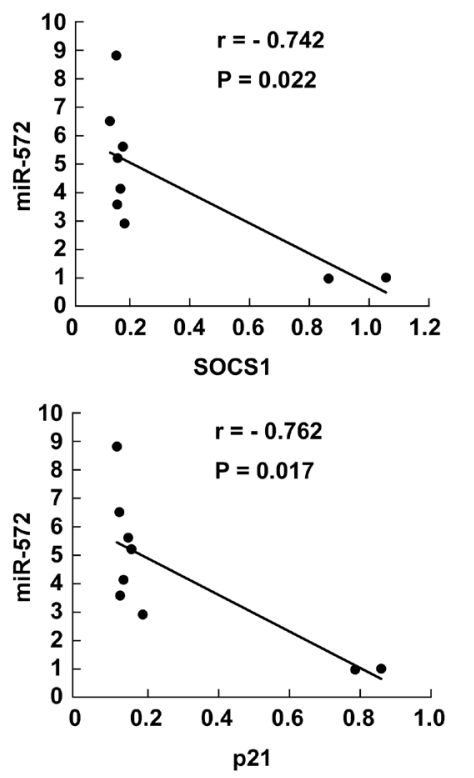

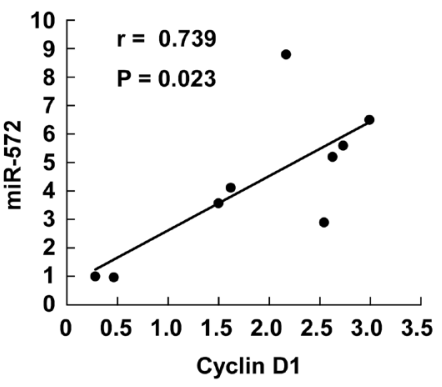

Cyclin D1

Figure 6: Expression of miR-572, SOCS1, p21 and Cyclin D1 in human ovarian cancer tissues. (A) Real-time PCR analysis of miR-572 and Western blot analysis of SOCS1, p21 and Cyclin D1 expression in human ovarian cancer tissues. (B) Correlation between miR-572 expression and SOCS1, p21 and Cyclin D1 expression in ovarian cancer tissues. Experiments were repeated at least three times with similar results; values are mean $\pm \mathrm{SD}$; ${ }^{*} P<0.05$.

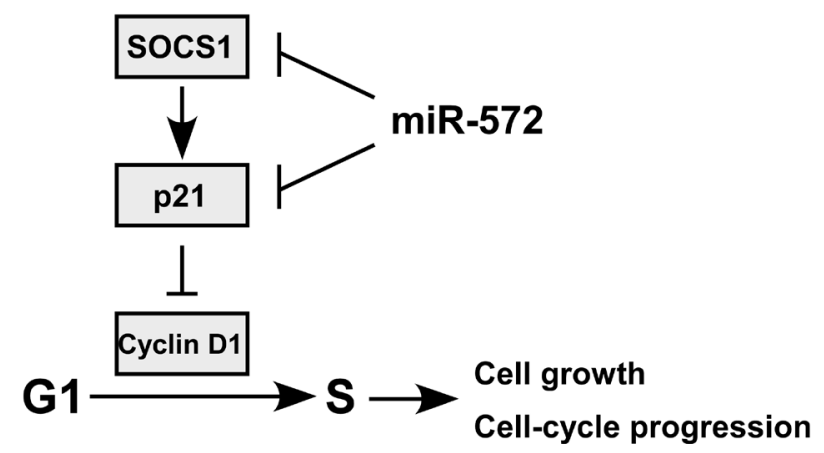

Figure 7: Proposed for model for the mechanism by which miR-572-mediated downregulation of SOCS1 and p21 promotes ovarian cancer cell proliferation 
negatively regulate activation of the Janus tyrosine kinase (JAK)/STAT pathway. SOCS1 is upregulated when a cytokine binds to its cognate receptor, and in turn SOCS1 inhibits JAK activity by binding to its catalytic domain and recruiting the ubiquitin-transferase complex to target JAK for proteasomal degradation, leading to inactivation of JAK-related signaling and inhibition of tumor cell growth [39]. SOCS1 also controls STAT and toll-like receptor (TLR) signaling to exert a tumor suppressive function. By regulating this negative feedback mechanism, SOCS1 can influence the transduction of proliferative signals and affect the survival, differentiation and transformation of $\mathrm{T}$ cells or tumor cells [14, 40, 41]. It has been reported that SOCS1 inhibits cell growth, induces senescence and modulates cell cycle arrest resulting in G1 arrest in $\mathrm{T}$ cells, fibroblasts or tumor cells, and these effects were associated with upregulation of p21 [19].

The potent CDKI p $21^{\mathrm{CIP} 1 / \mathrm{WAF} 1}$ binds and inhibits the CDK2, CDK1 and CDK4/6 complexes, and functions as a negative regulator of cell proliferation and cellcycle progression [16, 42]. For example, p21 inhibits cell proliferation by binding to and inhibiting Cyclin E/ CDK2 kinase activity, leading to growth arrest at specific stages in the cell cycle [43]. p53-induced upregulation of p21 in response to DNA damage induces cell cycle blockade in G1, followed by DNA repair or induction of apoptosis [44]. In addition, p21 binds to proliferating cell nuclear antigen (PCNA) and interferes with PCNAdependent DNA polymerase activity, thereby inhibiting DNA replication and modulating various PCNAdependent DNA repair processes $[45,46]$. Besides, p21 regulates gene transcription by directly associating with the promoter region of individual genes or by binding to specific transcription factors to modulate their activity. By directly controlling the activity of various tumor suppressors or oncogenes, p21 acts as an oncogene or tumor suppressor in different tumor types [47-49].

The evidence discussed above indicates that downregulation of SOCS1 and p21 may play essential roles in miR-572-induced tumor progression in ovarian cancer. However, the detailed regulatory network for miR-572, SOCS1 and p21, and the related signaling pathways are likely to be complicated and need further investigation. For example, it is already known that p21 is regulated by two different pathways: a p53-dependent pathway by which DNA damage leads to activation of p53 and upregulation of p21, and a p53-independent manner via which cellular growth factors, such as platelet-derived growth factor, fibroblast growth factor and epidermal growth factor induce p21 in p53-deficient quiescent cells [44]. The detailed regulatory mechanism of these factors has been under our further investigation.

Due to the ability of SOCS1 to inhibit various signaling pathways in tumor cells, the decreased expression of SOCS1 in cancer may represent a diagnostic and prognostic biomarker of clinical outcome in patients with myeloma, breast cancer, hepatocellular carcinoma, melanoma, or neuroendocrine tumor, suggesting SOCS1 may be a potential target for antitumor therapy $[14,15$, 50-52]. However, it has been reported that assessment of the expression of p21 and p53 or other genes may be more useful as a marker of tumor progression and prognosis in tongue squamous cell carcinomas and oral squamous cell carcinomas $[18,44]$, and overexpression of p21 alone appeared to be insufficient to suppress tumor progression [53]. Our study demonstrates that miR-572, which is overexpressed in human ovarian cancer, can target and suppress both SOCS1 and p21, leading to ovarian cancer progression. Therefore, our results indicate the potential value of miR-572 in ovarian cancer development and miR572 could be considered as useful biomarker for ovarian cancer diagnosis and prognosis. In addition, it was found that SOCS1 binds to p65 in the nucleus and operates as an E3 ligase that leads to polyubiquitination mediated proteasomal degradation of $\mathrm{p} 65$, resulting in suppression of p65 signaling and the expression of NF- $\kappa$ B signalingregulated genes [54]. Based on this study, whether miR572 performs its function via NF- $\kappa \mathrm{B}$ signaling in ovarian cancer needs to be further investigated.

Besides, consistent with our results, miR-572 was found upregulated in various malignancies [37, 38]. However, miR-572 was downregulated in gastric cancer cell lines compared to normal gastric mucosa [55]. Zhu et al. found significant downregulation of miR-572 in chronic lymphocytic leukemia [56]. Moreover, miR-572 was also reported downregulation in basal cell carcinoma [57]. These results suggest that the same miRNA can exert distinct biological activities under different cellular contexts.

In conclusion, miR-572 is overexpressed in ovarian cancer and upregulation of miR-572 promoted ovarian cancer cell proliferation, cell-cycle progression and tumorigenicity both in vitro and in vivo, while inhibition of miR-572 lead to the opposite effects. Moreover, the function of miR-572 in ovarian cancer may be exerted via downregulation of the target genes SOCS1 and p21, which play an important role in the function of miR-572 in ovarian cancer. Therefore, this study demonstrates that miR-572 may play an important role in ovarian cancer progression and may represent a potential therapeutic target for ovarian cancer therapy.

\section{MATERIALS AND METHODS}

\section{Cell culture and treatments}

Human ovarian epithelial cell (HOSEpiC) were purchased from Sciencell Research Labs (Carlsbad, CA, USA) and maintained according to the manufacturer's instruction. The ovarian cancer cell lines OVCAR3, 
SKOV3, TOV-21G, TOV-112D, A2780, CAOV3, CAOV4, OV56, OV90, COV362, COV434, COV504 and COV644 were maintained in RPMI 1640 (Invitrogen, Carlsbad, CA, USA) supplemented with 10\% FBS (Invitrogen), at $37^{\circ} \mathrm{C}$ in a $5 \% \mathrm{CO}_{2}$ atmosphere in a humidified incubator.

\section{Tissue specimens and patient information}

The 108 paraffin-embedded, archived ovarian cancer samples and freshly collected ovarian cancer tissue specimens used in this study were histopathologically and clinically diagnosed at the Sun Yat-sen University Cancer Center between 2008 and 2011. The disease stages of all the patients were classified according to the International Federation of Gynecology and Obstetrics (FIGO) guidelines for clinical staging. The clinicopathological characteristics of the samples are summarized in Supplemental Table 1. Normal ovarian tissues were obtained from individuals who underwent wedge biopsy of the ovaries and confirmed to be free of any pre-existing pathologically detectable conditions. All samples were collected and analyzed with prior written informed consent from the patients. Prior donors' consents and approvals from the Institutional Research Ethics Committee were obtained.

\section{Generation of stably engineered cell lines}

pMSCV-miR-572 was generated by cloning the genomic pre-miR-572 gene with about 500bp on each flanking side (primers used: forward, 5'-GCCAGATCTCTGAGGAAAGCAGGAGGAGG -3'; reverse, 5' - GCCGAATTCTCGG CACAAATCTTCAGAGC -3') into the retroviral transfer plasmid pMSCV-puro (Clontech Laboratories Inc., Mountain View, CA, USA). pMSCV-miR-572 was then cotransfected with the pIK packaging plasmid into 293FT cells, using the standard calcium phosphate transfection method [30]. Thirty-six hours after transfection, the supernatants were collected and then incubated with ovarian cancer cells to be infected for 24 hours in the presence of polybrene $(2.5 \mu \mathrm{g} / \mathrm{ml}$, Sigma, Saint Louis, MO, USA). Puromycin ( $1.5 \mu \mathrm{g} / \mathrm{ml}$, Sigma) was used to select stably transduced cells two weeks after infection.

\section{RNA extraction and real-time quantitative PCR}

Total cellular RNA was extracted using Trizol reagent (Invitrogen), according to the manufacturer's instruction. cDNAs were synthesized and real-time PCR was performed using the GoTaq ${ }^{\circledR}$ 2-Step RT-qPCR System (Promega, Madison, WI, USA). SYBR Green I (Invitrogen) was used to quantify PCR amplification and the qRT-PCR was performed and analyzed using a 7500 Fast Real-Time Sequence detection system (Applied Biosystems, Foster City, CA, USA). miRNA quantification was determined by using Bulge-loop ${ }^{\mathrm{TM}}$ miRNA qRT-PCR Primer Set (one RT primer and a pair of qPCR primers for each set) specific for miR-572, designed by RiboBio (RiboBio Co. Ltd, Guangzhou, Guangdong, China). The expression of the miRNA was defined based on $\mathrm{Ct}$, and relative expression levels were calculated as $2^{-[(\mathrm{Ct} \text { of } m i R-572)-}$ (Ct of $U$ )] after normalization with reference to the expression of small nuclear RNA U6. Expression levels of genes were normalized to that of the housekeeping gene GAPDH as the control and calculated as $2^{-[(\mathrm{Ct} \text { of GENES) - (Ct of GAPDH })]}$ $(\mathrm{Ct}$, represents the threshold cycle for each transcript). The following primers were used: Cyclin D1 forward, 5'-AACTACCTGGACCGCTTCCT-3', and reverse, 5'-CCACTTGAGCTTGTTCACCA-3'. GAPDH forward: 5'- GACTCAT GACCACAGTCCATGC -3', reverse: 3'AGAGGCAGGGATGATGTTCTG -5'.

\section{Oligonucleotides, siRNA and transfection}

The miR-572 anti-sense (miRZip-572) plasmid used as miR-572 inhibitor, and the vector control (miRZipVector) were purchased from System Biosciences (San Francisco, CA) and used according to previous report [31]. For depletion of SOCS1-, and p21-siRNAs were synthesized and purified by RiboBio. Transfection of oligonucleotides and siRNAs were performed using the Lipofectamine 2000 reagent (Invitrogen), according to the manufacturer's instruction.

\section{Western blotting analysis}

Total protein was extracted from whole cells and $20 \mu \mathrm{g}$ of isolated protein was separated by SDS-PAGE and electroblotted onto a PVDF membrane (Bio-Rad Laboratories, Hercules, CA, USA). The membranes were then probed with antibodies: anti-SOCS1, anti-p21, anti-Cyclin D1 (Abcam, Cambridge, MA, USA). The membranes were stripped and reblotted with an anti- $\alpha$ tubulin monoclonal antibody (Sigma) as a loading control.

\section{Colony formation assay}

Cells were plated on 6-well plate (1000 cells per dish) and cultured for 10 days. The colonies were stained with $0.1 \%$ crystal violet for 5 min after fixation with $10 \%$ formaldehyde for $15 \mathrm{~min}$. Viable colonies that contained more than 50 cells were counted. The experiment was performed for three independently times for each cell line. 


\section{Anchorage-independent growth ability assay}

Cells $\left(1 \times 10^{3}\right)$ were trypsinized and suspended in 2 $\mathrm{ml}$ complete medium plus $0.33 \%$ agar (Invitrogen) and plated in 6-well plate on top of a bottom agar layer $(0.66 \%$ complete medium agar). After two-week days incubation, colony sizes were measured with an ocular micrometer and colonies greater than $0.1 \mathrm{~mm}$ in diameter were counted. All experiments were performed in triplicate.

\section{Bromodeoxyuridine immunofluorescence}

labeling and

Cells grown on coverslips (Fisher, Pittsburgh, PA, USA) were incubated with bromodeoxyuridine (BrdUrd) for $1 \mathrm{~h}$ and stained with anti-BrdUrd antibody (Sigma) according to the manufacturer's instruction. Gray level images were acquired under a laser scanning microscope (Axioskop 2 plus, Carl Zeiss Co. Ltd., Jena, Germany). All experiments were performed in triplicate.

\section{Flow cytometry analysis}

All cells in a culture dish were harvested by trypsinization, washed in ice-cold PBS, and fixed in $80 \%$ ice-cold ethanol in PBS. Before staining, the cells were spun down in a cooled centrifuge and resuspended in the cold PBS. Bovine pancreatic RNAase (Sigma) was added at a final concentration of $2 \mu \mathrm{g} / \mathrm{ml}$, and cells were incubated at $37^{\circ} \mathrm{C}$ for $30 \mathrm{~min}$, followed by incubation in $20 \mu \mathrm{g} / \mathrm{ml}$ of propidium iodide (Sigma) for $20 \mathrm{~min}$ at room temperature. Fifty thousand cells were analyzed flow cytometrically. All experiments were performed in triplicate.

\section{Luciferase assay}

Cells were seeded in triplicate in 24-well plate and allowed to settle for about $12 \mathrm{~h}$. One hundred nanograms of pGL3-SOCS1, or - p21-luciferase plasmid was cotransfected into ovarian cancer cells with TK-Renilla plasmid as control signals using the Lipofectamine 2000 reagent, according to the manufacturer's instruction. Luciferase and control signals were measured at $48 \mathrm{~h}$ after transfection using the Dual Luciferase Reporter Assay Kit (Promega, Madison, WI, USA), according to a protocol provided by the manufacturer. Three independent experiments were performed and the data were presented as the mean $\pm \mathrm{SD}$.

\section{Xenografted tumor model}

BALB/c-nude mice (female, 4-5 weeks of age, 18$20 \mathrm{~g}$ ) were purchased from the Center of Experimental Animal of Guangzhou University of Chinese Medicine. All experimental procedures were approved by the Institutional Animal Care and Use Committee of Sun Yat-sen University. The BALB/c nude mice were randomly divided into two groups. One group of mice was inoculated subcutaneously with SKOV3/Vector cells $\left(5 \times 10^{6}\right)$ in the left dorsal flank and with SKOV3/miR-572 cells $\left(5 \times 10^{6}\right)$ in the right dorsal flank per mouse. Another group was inoculated subcutaneously with SKOV3/ miRZip-Vector cells $\left(5 \times 10^{6}\right)$ in the left dorsal flank and with SKOV3/miRZip-572 cells $\left(5 \times 10^{6}\right)$ in the right dorsal flank. Tumors were examined once every 4 days; length, width, and thickness were measured with callipers, and tumor volumes were calculated. Tumor volume was calculated using the equation $\left(\mathrm{L}^{*} \mathrm{~W}^{2}\right) / 2$. Forty days after tumor implantation, the mice were killed, the tumors were removed and weighed.

\section{Statistical analysis}

Student's $t$ test was used to evaluate the significant difference between two groups of data in all the pertinent experiments. The experimental data were represented from three biological independent replicates and as the mean \pm SD. Bivariate correlations between study variables were calculated by Spearman's rank correlation coefficients. Survival curves were plotted by the Kaplan-Meier method and compared by the log-rank test. A $P$ value $<0.05$ (using a two-tailed paired $t$ test) was considered statistically significant.

\section{ACKNOWLEDGEMENTS}

This work was supported by grants from the National Natural Scientific Foundation of China (No. 81101680, 81325013, 91229101); Science and Technology Planning Project of Guangdong Province, China (No. 2013B021800096); The Guangzhou scholars research projects of Guangzhou municipal colleges and universities (No. 12A009D); Pearl River projects (Young Talents of Science and Technology) in Guangzhou (No. 2013J2200028). The open projects of State Key Laboratory of Oncology in Southern China (No. HN201304).

\section{CONFLICTS OF INTEREST}

None declared. 


\section{REFERENCES}

1. Rezk Y, Timmins PF, 3rdandSmith HS. Review article: palliative care in gynecologic oncology. The American journal of hospice \& palliative care. 2011; 28:356-374.

2. Stewart BW, Wild, CP: World Cancer Report 2014. vol. Chapter 5.12: World Health Organization; 2014: 2014.

3. Cohen JG, White M, Cruz AandFarias-Eisner R. In 2014, can we do better than CA125 in the early detection of ovarian cancer? World journal of biological chemistry. 2014; 5:286-300.

4. Brain KE, Smits S, Simon AE, Forbes LJ, Roberts C, Robbe IJ, Steward J, White C, Neal RD, Hanson JandGroup IMW. Ovarian cancer symptom awareness and anticipated delayed presentation in a population sample. BMC cancer. 2014; $14: 171$.

5. Menon U, Griffin MandGentry-Maharaj A. Ovarian cancer screening--current status, future directions. Gynecologic oncology. 2014; 132:490-495.

6. Ovarian cancer awareness. Australian nursing \& midwifery journal. 2014; $21: 11$

7. Herzog TJ. The current treatment of recurrent ovarian cancer. Current oncology reports. 2006; 8:448-454.

8. Jones R, GandThompson CB. Tumor suppressors and cell metabolism: a recipe for cancer growth. Genes \& development. 2009; 23:537-548.

9. DeBerardinis RJ, Lum JJ, Hatzivassiliou GandThompson CB. The biology of cancer: metabolic reprogramming fuels cell growth and proliferation. Cell metabolism. 2008; 7:1120.

10. Zhang J, Li H, Yu JP, Wang SEandRen XB. Role of SOCS1 in tumor progression and therapeutic application. International journal of cancer Journal international du cancer. 2012; 130:1971-1980.

11. Waiboci LW, Ahmed CM, Mujtaba MG, Flowers LO, Martin JP, Haider MIandJohnson HM. Both the suppressor of cytokine signaling 1 (SOCS-1) kinase inhibitory region and SOCS-1 mimetic bind to JAK2 autophosphorylation site: implications for the development of a SOCS-1 antagonist. Journal of immunology. 2007; 178:5058-5068.

12. Kazi JU, Kabir NN, Flores-Morales AandRonnstrand L. SOCS proteins in regulation of receptor tyrosine kinase signaling. Cellular and molecular life sciences : CMLS. 2014; 71:3297-3310.

13. Okochi O, Hibi K, Sakai M, Inoue S, Takeda S, Kaneko TandNakao A. Methylation-mediated silencing of SOCS1 gene in hepatocellular carcinoma derived from cirrhosis. Clinical cancer research : an official journal of the American Association for Cancer Research. 2003; 9:5295-5298.

14. Galm O, Yoshikawa H, Esteller M, Osieka RandHerman JG. SOCS-1, a negative regulator of cytokine signaling, is frequently silenced by methylation in multiple myeloma. Blood. 2003; 101:2784-2788.

15. Sasi W, Jiang WG, Sharma AandMokbel K. Higher expression levels of SOCS 1,3,4,7 are associated with earlier tumour stage and better clinical outcome in human breast cancer. BMC cancer. 2010; 10:178.

16. Gartel ALandRadhakrishnan SK. Lost in transcription: p21 repression, mechanisms, and consequences. Cancer research. 2005; 65:3980-3985.

17. Kapranos N, Stathopoulos GP, Manolopoulos L, Kokka E, Papadimitriou C, Bibas A, Yiotakis JandAdamopoulos G. p53, p21 and p27 protein expression in head and neck cancer and their prognostic value. Anticancer research. 2001; 21:521-528.

18. Xie X, Clausen OPandBoysen M. Prognostic significance of p21WAF1/CIP1 expression in tongue squamous cell carcinomas. Archives of otolaryngology--head \& neck surgery. 2002; 128:897-902.

19. Calabrese V, Mallette FA, Deschenes-Simard X, Ramanathan S, Gagnon J, Moores A, Ilangumaran SandFerbeyre G. SOCS1 links cytokine signaling to p53 and senescence. Molecular cell. 2009; 36:754-767.

20. Dai B, Hu Z, Huang H, Zhu G, Xiao Z, Wan W, Zhang $\mathrm{P}$, Jia WandZhang L. Overexpressed KDM5B is associated with the progression of glioma and promotes glioma cell growth via downregulating p21. Biochemical and biophysical research communications. 2014; 454:221-227.

21. Dhyani A, Machado-Neto JA, Favaro PandSaad ST. ANKHD1 represses p21 (WAF1/CIP1) promoter and promotes multiple myeloma cell growth. European journal of cancer. 2014; 51:252-259.

22. Jin LandDatta PK. Oncogenic STRAP functions as a novel negative regulator of E-cadherin and $\mathrm{p} 21$ by modulating the transcription factor Sp1. Cell cycle. 2014; 24:3909-3920.

23. Ambros V. The functions of animal microRNAs. Nature. 2004; 431:350-355.

24. Bartel DP. MicroRNAs: genomics, biogenesis, mechanism, and function. Cell. 2004; 116:281-297.

25. Ruvkun G. Clarifications on miRNA and cancer. Science. 2006; 311:36-37.

26. Calin GAandCroce CM. MicroRNA signatures in human cancers. Nat Rev Cancer. 2006; 6:857-866.

27. Cimmino A, Calin GA, Fabbri M, Iorio MV, Ferracin M, Shimizu M, Wojcik SE, Aqeilan RI, Zupo S, Dono M, Rassenti L, Alder H, Volinia S, Liu CG, Kipps TJ, Negrini MandCroce CM. miR-15 and miR-16 induce apoptosis by targeting BCL2. Proc Natl Acad Sci U S A. 2005; 102:13944-13949.

28. Godlewski J, Nowicki MO, Bronisz A, Williams S, Otsuki A, Nuovo G, Raychaudhury A, Newton HB, Chiocca EAandLawler S. Targeting of the Bmi-1 oncogene/stem cell renewal factor by microRNA-128 inhibits glioma proliferation and self-renewal. Cancer Res. 2008; 68:91259130.

29. Cho WC. OncomiRs: the discovery and progress of microRNAs in cancers. Mol Cancer. 2007; 6:60.

30. Hahn WC, Dessain SK, Brooks MW, King JE, Elenbaas B, 
Sabatini DM, DeCaprio JAandWeinberg RA. Enumeration of the simian virus 40 early region elements necessary for human cell transformation. Mol Cell Biol. 2002; 22:21112123.

31. Gong H, Song L, Lin C, Liu A, Lin X, Wu J, Li MandLi J. Downregulation of miR-138 sustains NF-kappaB activation and promotes lipid raft formation in esophageal squamous cell carcinoma. Clinical cancer research : an official journal of the American Association for Cancer Research. 2013; 19:1083-1093.

32. Casalini PandIorio MV. MicroRNAs and future therapeutic applications in cancer. J BUON. 2009; 14 Suppl 1:S17-22.

33. Nana-Sinkam SPandCroce CM. MicroRNAs as therapeutic targets in cancer. Transl Res. 2011; 157:216-225.

34. Sun J, Lu H, Wang XandJin H. MicroRNAs in hepatocellular carcinoma: regulation, function, and clinical implications. ScientificWorldJournal. 2013; 2013:924206.

35. Krell J, Frampton AEandStebbing J. MicroRNAs in the cancer clinic. Front Biosci (Elite Ed). 2013; 5:204-213.

36. Liu N, Cui RX, Sun Y, Guo R, Mao YP, Tang LL, Jiang W, Liu X, Cheng YK, He QM, Cho WC, Liu LZ, Li LandMa J. A four-miRNA signature identified from genome-wide serum miRNA profiling predicts survival in patients with nasopharyngeal carcinoma. International journal of cancer Journal international du cancer. 2014; 134:1359-1368.

37. Wang $\mathrm{C}, \mathrm{Hu} \mathrm{J}, \mathrm{Lu} \mathrm{M}, \mathrm{Gu} \mathrm{H}$, Zhou X, Chen X, Zen K, Zhang CY, Zhang T, Ge J, Wang JandZhang C. A panel of five serum miRNAs as a potential diagnostic tool for earlystage renal cell carcinoma. Scientific reports. 2015; 5:7610.

38. Li M, Lu N, Liu HX, Chen DBandZhang JZ. [Expression profiling of microRNA and their target genes in peripheral T cell lymphoma, not otherwise specified]. Zhonghua bing li xue za zhi Chinese journal of pathology. 2013; 42:519524.

39. Inagaki-Ohara K, Kondo T, Ito MandYoshimura A. SOCS, inflammation, and cancer. Jak-Stat. 2013; 2:e24053.

40. Palmer DCandRestifo NP. Suppressors of cytokine signaling (SOCS) in T cell differentiation, maturation, and function. Trends in immunology. 2009; 30:592-602.

41. Cooper JC, Shi M, Chueh FY, Venkitachalam SandYu CL. Enforced SOCS1 and SOCS3 expression attenuates Lckmediated cellular transformation. International journal of oncology. 2010; 36:1201-1208.

42. Gartel AL, Serfas MSandTyner AL. p21--negative regulator of the cell cycle. Proceedings of the Society for Experimental Biology and Medicine Society for Experimental Biology and Medicine. 1996; 213:138-149.

43. Harper JW, Adami GR, Wei N, Keyomarsi KandElledge SJ. The p21 Cdk-interacting protein Cip1 is a potent inhibitor of G1 cyclin-dependent kinases. Cell. 1993; 75:805-816.

44. Kudo Y, Takata T, Ogawa I, Sato SandNikai H. Expression of p53 and p21CIP1/WAF1 proteins in oral epithelial dysplasias and squamous cell carcinomas. Oncology reports. 1999; 6:539-545.
45. Abbas TandDutta A. p21 in cancer: intricate networks and multiple activities. Nat Rev Cancer. 2009; 9:400-414.

46. Funk JO, Waga S, Harry JB, Espling E, Stillman BandGalloway DA. Inhibition of CDK activity and PCNAdependent DNA replication by $\mathrm{p} 21$ is blocked by interaction with the HPV-16 E7 oncoprotein. Genes Dev. 1997; 11:2090-2100.

47. Chang BD, Watanabe K, Broude EV, Fang J, Poole JC, Kalinichenko TVandRoninson IB. Effects of p21Waf1/ Cip1/Sdil on cellular gene expression: implications for carcinogenesis, senescence, and age-related diseases. Proc Natl Acad Sci U S A. 2000; 97:4291-4296.

48. Coqueret OandGascan H. Functional interaction of STAT3 transcription factor with the cell cycle inhibitor p21WAF1/ CIP1/SDI1. J Biol Chem. 2000; 275:18794-18800.

49. Fritah A, Saucier C, Mester J, Redeuilh GandSabbah M. p21WAF1/CIP1 selectively controls the transcriptional activity of estrogen receptor alpha. Mol Cell Biol. 2005; 25:2419-2430.

50. Wu LM, Zhang F, Zhou L, Yang Z, Xie HYandZheng SS. Predictive value of $\mathrm{CpG}$ island methylator phenotype for tumor recurrence in hepatitis B virus-associated hepatocellular carcinoma following liver transplantation. BMC cancer. 2010; 10:399.

51. Lesinski GB, Zimmerer JM, Kreiner M, Trefry J, Bill MA, Young GS, Becknell BandCarson WE, 3rd. Modulation of SOCS protein expression influences the interferon responsiveness of human melanoma cells. BMC cancer. 2010; 10:142.

52. Zitzmann K, Brand S, De Toni EN, Baehs S, Goke B, Meinecke J, Spottl G, Meyer HHandAuernhammer CJ. SOCS1 silencing enhances antitumor activity of type I IFNs by regulating apoptosis in neuroendocrine tumor cells. Cancer research. 2007; 67:5025-5032.

53. $\mathrm{Ng}$ IO, Lam KY, Ng MandRegezi JA. Expression of p21/ waf1 in oral squamous cell carcinomas--correlation with p53 and mdm2 and cellular proliferation index. Oral oncology. 1999; 35:63-69.

54. Strebovsky J, Walker P, Lang RandDalpke AH. Suppressor of cytokine signaling 1 (SOCS1) limits NFkappaB signaling by decreasing p65 stability within the cell nucleus. FASEB journal : official publication of the Federation of American Societies for Experimental Biology. 2011; 25:863-874.

55. Yu BQ, Su LP, Li JF, Cai Q, Yan M, Chen XH, Yu YY, Gu QL, Zhu ZGandLiu BY. microrna expression signature of gastric cancer cells relative to normal gastric mucosa. Molecular medicine reports. 2012; 6:821-826.

56. DX. Z, W. Z, C. F, L. F, ZJ. Z, YH. W, P. L, M. H, KR. M, P. L, W. XandJY. L. miR-181a/b significantly enhances drug sensitivity in chronic lymphocytic leukemia cells via targeting multiple anti-apoptosis genes. Carcinogenesis. 2012; 33:1294-1301.

57. Sand M, Skrygan M, Sand D, Georgas D, Hahn SA, Gambichler T, Altmeyer PandBechara FG. Expression of 
microRNAs in basal cell carcinoma. The British journal of dermatology. 2012; 167:847-855. 